\title{
A Modern Mechanisam and Functioning of Bus Transit using Rfid and Gps Based System
}

\author{
V.Geetha, C.K.Gomathy, Nirnipreetham, Ponugotipavan kumar
}

\begin{abstract}
Right now present transport a framework which kept stationary at the transport stand and framework which kept at transport that can adequately assist general society with participating in transport transportation offices to its fullest. A transport that is coming toward the transport - stop is recognized by this traveller through one of a kind traveller card the subtleties of that specific transport is given to the traveller in plain view at transport stand. Transport area recognized utilizing GPS and same will be declare in Bus This data send to next bus station for travellers. The transport distinguishing proof procedure includes use of Radio Frequency innovation and transport subtleties are reported by Voice and showed in screen unit. Subtleties incorporate the specific situation of the transport, seat accessibility and absolute number of travellers. This data can be shown on screen or can be given as sound yield. Here both transport and transport stop is interconnected through IOT, here we use MQTT convention for correspondence.
\end{abstract}

Keywords: RFID tag, GPS, Automated ticketing, RTOS

\section{INTRODUCTION}

The development of school transports is influenced by various unsure conditions as the day advances, for example, traffic blockage, unforeseen deferrals, and haphazardness in traveller request, sporadic vehicle-dispatching times and a lot more occurrences. Numerous understudies and staff individuals are frequently late for school since they choose to sit tight for the transport as opposed to utilizing a substitute transportation. To lessen this disarray and burden, a message will be appeared on the web that will give the ongoing data about the transport demonstrating its appearance time which could decrease the tension of travellers hanging tight for the transport. With[4] the approach of GPS and the inescapable cell organize, constant vehicle following for better vehicle the executives has gotten conceivable. These innovations can be applied to move frameworks particularly transports, which are not ready to hold fast to predefined timetables because of reasons like congested driving conditions, breakdowns and so on. The expanded holding up time and the vulnerability in transport appearance make open vehicle framework ugly and illogical for travellers to deal with their day by day transportation.

Revised Manuscript Received on June 30, 2020.

* Correspondence Author

Dr. V.Geetha*, Assistant Professor in CSE Department, SCSVMV Deemed to be University.

Dr. C.K.Gomathy, Assistant Professor in CSE Department, SCSVMV Deemed to be University

Nirnipreetham, UG Scholar CSE Department, SCSVMV Deemed to be University

Ponugotipavan kumar, UG Scholar CSE Department, SCSVMV Deemed to be University

(C) The Authors. Published by Blue Eyes Intelligence Engineering and Sciences Publication (BEIESP). This is an open access article under the CC BY-NC-ND license (http://creativecommons.org/licenses/by-nc-nd/4.0/)
The continuous transport following framework utilizes GPS (Global Positioning System) innovation to get information and presentations the information utilizing programming permitting a client to screen a specific transport on a specific course. At the point when this data is[5] displayed to the traveller by remote media or online web media, they can deal with their time proficiently and arrive at the bus station not long before the transport shows up, or take a substitute methods for transport if the transport is postponed. They can even arrangement their excursions well before they really start them. The constant following of the transport should be possible by our proposed framework and this data is then given to a remote client who needs to realize the ongoing transport data.

\section{II. LITERATURE SURVEY}

The bus management system for RFID using WSN" titled by Ben AmmarHatim for smart city it describes the approach to use radio frequency identification used for the read range identification of the system. We can know the environment and optimization of the subject using wireless[1] sensor network then the idea to improvise rfid technologies using wireless is studied the proposed methodology describes the real time location of the bus from the bus station these provides information to the user about the bus arrival time or delay this information of the real time is then displayed on the displays which is connected to the bus stop. "The RFID based ticketing for public transport system"[2], which works on the public ticketing transport for smart city he introduces severe malfunction and the mass argument between the public in the system. This paper subjects on public friendly, automated ticket system as well as the cancellation of the ticketing using radio frequency identification this system mainly concentrates on bringing out the consistency between all bus agencies that comes under uniform accessing passengers who takes daily transport through an automated server. "GPS talking by blind people" titled by Ammer H. Morad, in order to help the blind people he designed a device which navigates the environment . he designed the device using GPS the located data where the blind stands is detected by the GPS receiver, pic controller process this data to find the real coordinated current location, then through the hand set the device translates into the specific voice.the main aim of the design by using very few components that is more cheap and easy to use for a blind person." an intelligent voice enabled distance to empty and navigation system" by DhurbaNingombam which deals about the fast growing automobile sector in recent years ,

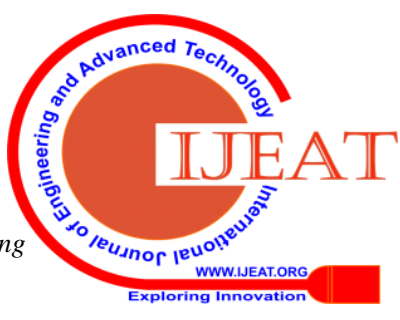




\section{A Modern Mechanisam and Functioning of Bus Transit using Rfid and Gps Based System}

leading to increased urge for an man machine interaction system for navigation. This paper mainly deals with the implementation and development of intelligent speech based system and DTE calculation for specified land vehicle application. This system works using GPS [3]for determining the current location and the input of the system for the destination is done by voice command and the output for the distance road and the amount of fuel required by speech and then the current location on the map along with the prediction is displayed how much long it can travel by remaining fuel." A User centred design approach to self servicing ticket vending machine" by Karin siebenhadl has become an important mode of transpotation channel in public which barriers do currently hind the usage of tvm and these tvms where contrast in post- hoc evaluations this approach that takes the needs of the different target groups into account throughout the whole development process.

\section{METHODOLOGY}

- Conventional transport stop

- Information of all transports are given

- No live following

- No card based installment

\section{BLOCK DIAGRAM :}

Bus stop node
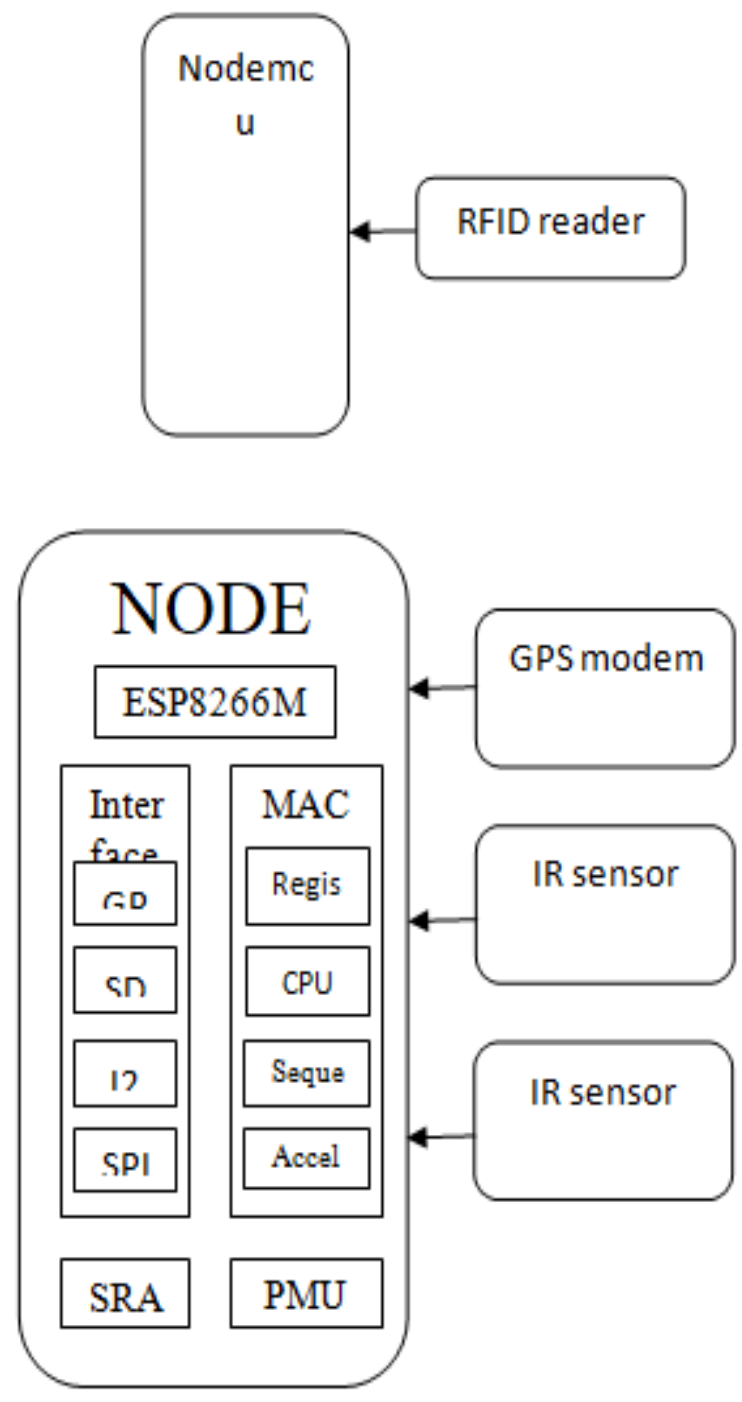

Fig 1:Block diagram for BUS node

\section{Equipment REQUIREMENT :}

- $\quad$ Nodemcu

- $\quad$ RFID peruser

- $\quad$ GPS modem

- $\quad$ IR sensor

\section{Programming REQUIREMENT :}

- Programming condition: Arduino IDE

- $\quad$ Programming language: implanted C

\section{Square DIAGRAM :}

- $\quad$ Here we have two hubs

- Bus stop hub is made with Nodemcu

- RFID peruser is associated sequentially to Nodemcu utilizing $\mathrm{Rx}$ and Tx pins of UART

- RFID is utilized for client distinguishing proof

- Nodemcu is utilized for transport hub

- $\quad$ GPS modem is associated sequentially same as RFID

- Both hubs are associated through MQTT convention

\section{FLEET MANAGEMENT FLOW SYSTEM}

The flow diagram shows how the GPS data is shared from driver application to the smart fleet application which makes the tracking of that particular vehicle possible. The data flow is like

1. Acquiring GPS data using GPS location service in mobile phone.

2. Smart Driver application sends this data to the real time database server.

3. This data is fetched by the Smart Fleet application in users mobile.

4. The Smart Fleet application show the live location on the map.

Smart Driver

- Driver Registration-The user has to login to the Smart Driver application and then register the driver selecting from the list of drivers.

- Driver Login-The registered driver by the user can login to the Smart Driver application.

- Navigation-The Driver can navigate to the preferred destination given by the user using this functionality. The navigation screen shows the directions to the destination.
Published By:

Blue Eyes Intelligence Engineering $\&$ Sciences Publication (c) Copyright: All rights reserved.

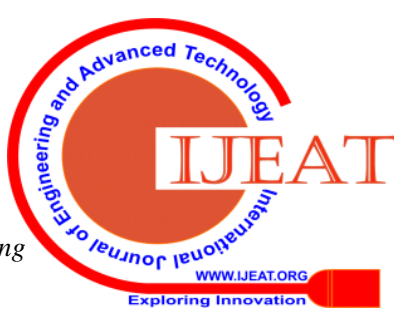




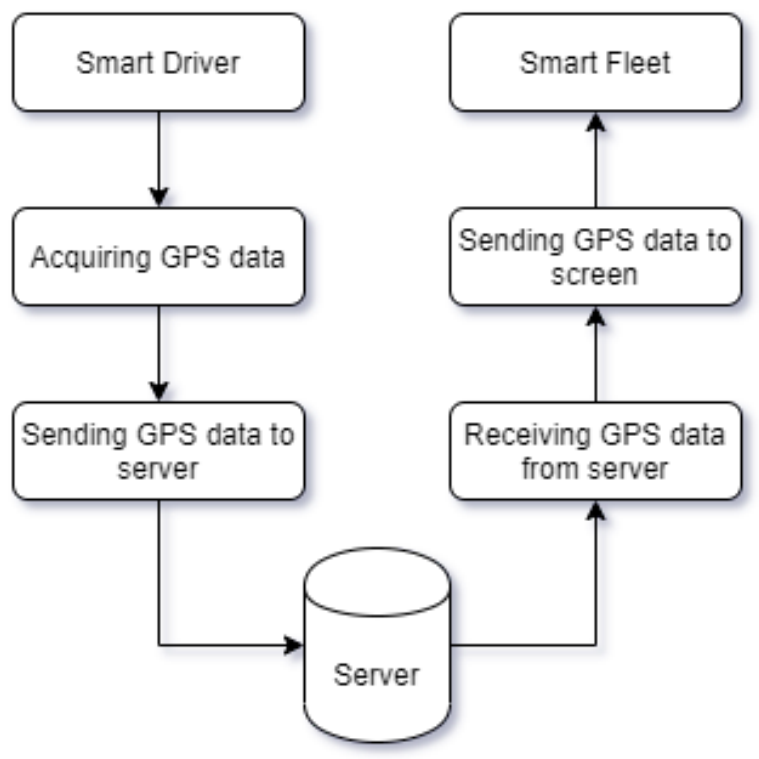

Flow Diagram

FIG 2: fleet management flow system

\section{PRINCIPLES OF WORKING MODEL}

\section{Module 1}

\section{NODE MCU}

Its an open source IoT platform .It is the Node Microcontroller Unit (node MCU), which controls the whole system. All the sensors are interfaced using this controller.

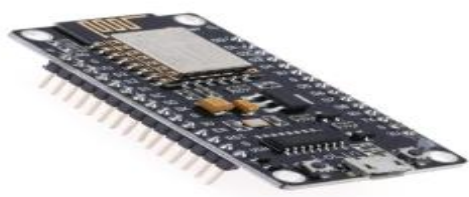

Fig 3:microcontroller

Module 2

\section{GPS modules}

GPS is used to detect the Latitude and Longitude of any location on the Earth, with exact UTC time (Universal Time Coordinated). Whenever there is an occurrence of high heartbeat rate the location will be shared for authorized person.

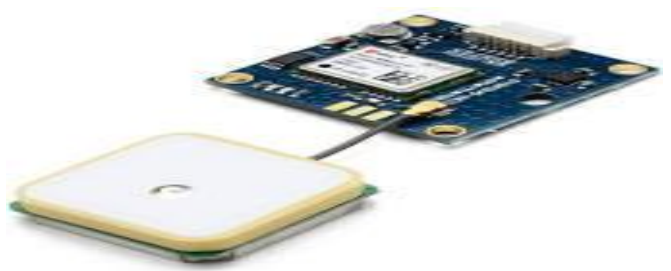

Fig 4: GPS

\section{Module 3}

\section{RFID}

- $\quad$ RFID reader is connected serially to Nodemcu using RX and TX pins of UART

- $\quad$ RFID is used for customer identification
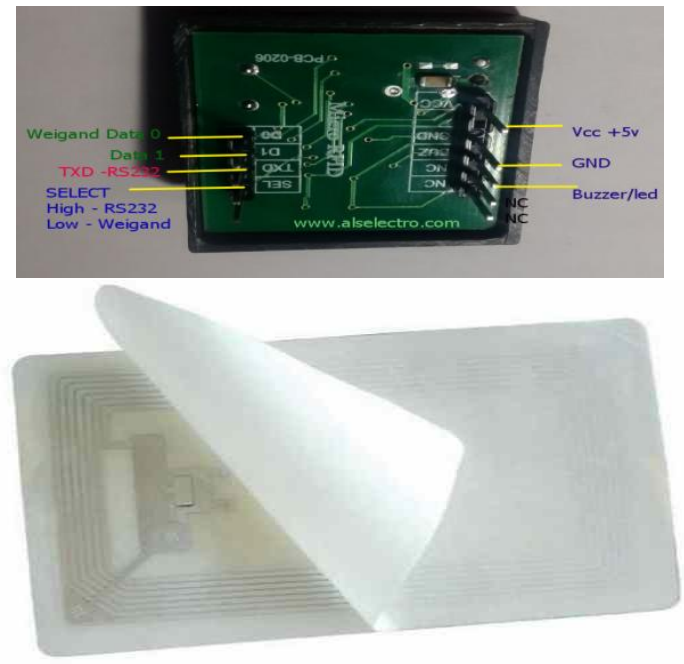

Fig 5: RFID

VI. RESULTS

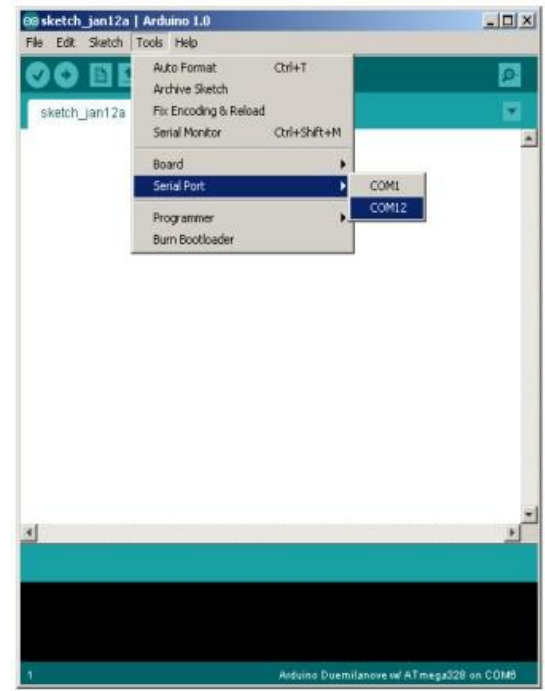

\section{A:Arduino IDE}

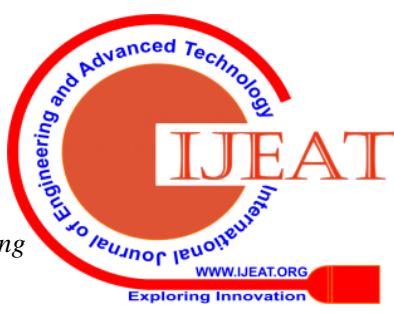




\section{A Modern Mechanisam and Functioning of Bus Transit using Rfid and Gps Based System}

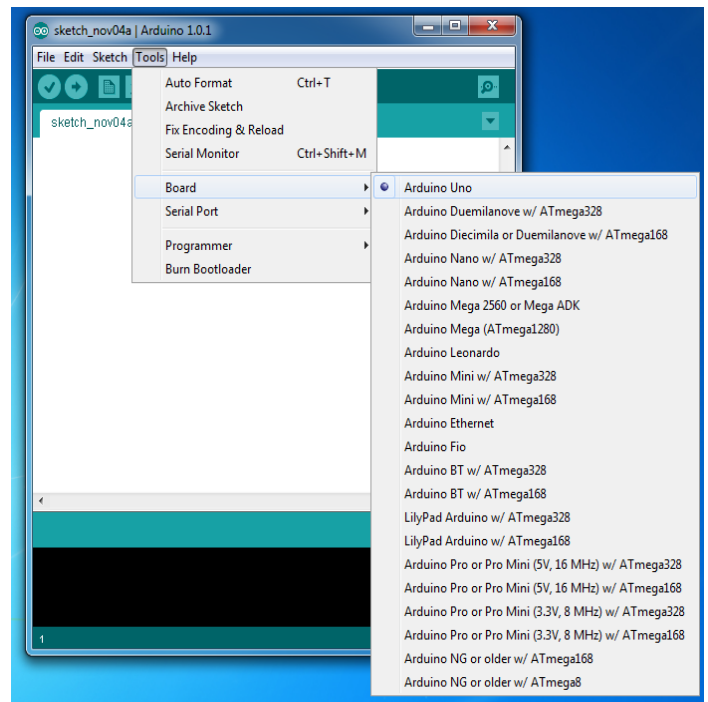

B:Select Serial Port and Board

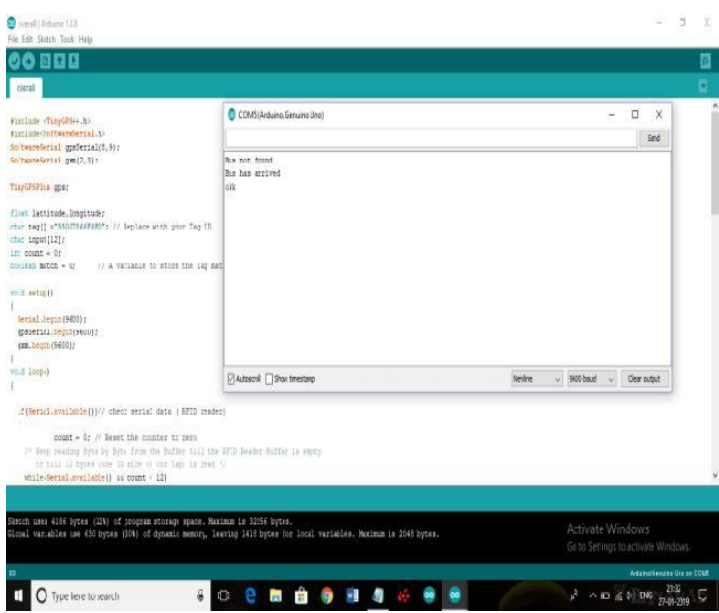

C:Simulation in Arduino IDE

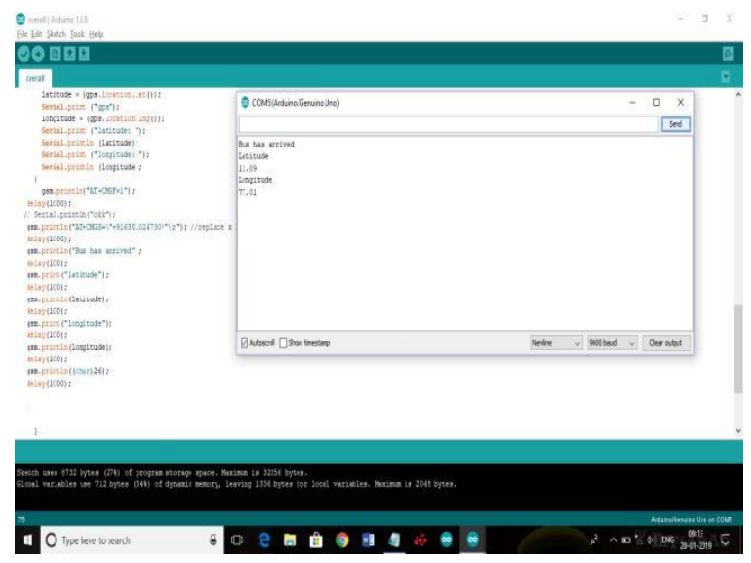

D: Output message obtained

\section{CONCLUSION}

The existing mechanism problems have been cleared by making it more automated and reliable. This can be implemented in a very convenient way in a large scale industry at the important cities in India. Fare is debited. It is by using RFID Tags and it is rechargeable. We are trying to propose this kind of RFID based tickets at the cost very low, operation, should be very easy, portability, reliability and it is being more user friendly. The high speed RFID tags and detectors is making the moving bus tracking system purely child's play.

\section{REFERENCES:}

1. J. Enrique Fernandez L., Joaquin de Cea Ch., and R. Henry Malbran, Demand responsive urban public transport system design: Methodology and application. Transportation Research Part A: Policy and Practice, ISSN: 0965-8564, Vol: 42, Issue: 7, pp. $951-972$ (2008)

2. Jerrin George James, Sreekumar Nair "Proficient, Real-time Tracking of Public Transport, Using LoRaWAN and RF Transceivers" Proc. of the 2017 IEEE Region 10 Conference (TENCON), Malaysia, November 5-8, 2017

3. Sarah Aimi Saad, Amirah 'Aisha BadrulHisham, Mohamad HafisIzranIshak , Mohd Husaini Mohd Fauzi , Muhammad AriffBaharudin , NurulHawani Idris "Continuous on-Campus Public Transportation Monitoring System " IEEE fourteenth International Colloquium on Signal Processing and its Applications (CSPA 2018), 9 - 10 March 2018.

4. A.P. Silva, G.R.Mateus and R.P.L.Xavier, A Mobile User LocationBased Bus Service Application, SIMULATION SERIES, 2004

5. Nusrath Jahan, Kamal Hossen and Muhammad Kamrul, Hossain Patwary "Usage of a Vehicle Tracking System utilizing Smartphone and SMS administration" 2017 fourth International Conference on Advances in Electrical Engineering (ICAEE) 28-30 September.

6. Darshan Ingle, Dr. A. B. Bagwan" Real-Time Analysis and Simulation of Efficient Bus Monitoring System" second International gathering on Electronics, Communication and Aerospace Technology (ICECA 2018)

7. Dr.C K Gomathy, Article: A Semantic Quality of Web Service Information Retrieval Techniques Using Bin Rank A Cloud Monitoring Framework Perform in Web Services, International Journal of Scientific Research in Computer Science Engineering and Information Technology IJSRCSEIT | Volume 3 | Issue 5 | ISSN 2456-3307,May-2018

8. Dr.C K Gomathy, Article: A Web Based Platform Comparison by an Exploratory Experiment Searching For Emergent Platform Properties, IAETSD Journal For Advanced Research In Applied Sciences, Volume 5, Issue 3, P.No-213-220, ISSN NO: 2394-8442,Mar/2018

9. C K Gomathy and V Geetha. Article: Evaluation on Ethernet based Passive Optical Network Service Enhancement through Splitting of Architecture. International Journal of Computer Applications 138(2):14-17, March 2016. Published by Foundation of Computer Science (FCS), NY, USA, ISSN No: 0975-8887

10. C K Gomathy and V Geetha. Article: A Real Time Analysis of Service based using Mobile Phone Controlled Vehicle using DTMF for Accident Prevention. International Journal of Computer Applications 138(2):11-13, March 2016. Published by Foundation of Computer Science (FCS), NY, USA,ISSN No: 0975-8887
Published By:

Blue Eyes Intelligence Engineering

\& Sciences Publication

(C) Copyriaht: All riahts reserved. 